OPEN ACCESS

Edited by:

Hemraj B. Dodiya,

University of Chicago,

United States

Reviewed by:

David R. Brown,

University of Minnesota Twin Cities,

United States

Christopher B. Forsyth,

Rush University, United States

*Correspondence:

Per E. J. Saris

per.saris@helsinki.fi

Kari E. Murros

kari.murros@terveystalo.com

${ }^{\dagger}$ These authors have contributed equally to this work and share first authorship

Specialty section:

This article was submitted to Microbiome in Health and Disease, a section of the journal

Frontiers in Cellular and Infection Microbiology

Received: 14 January 2021 Accepted: 19 April 2021 Published: 03 May 2021

Citation:

Murros KE, Huynh VA, Takala TM and

Saris PEJ (2021) Desulfovibrio

Bacteria Are Associated

With Parkinson's Disease.

Front. Cell. Infect. Microbiol. 11:652617.

doi: 10.3389/fcimb.2021.652617

\section{Desulfovibrio Bacteria Are Associated With Parkinson's Disease}

\author{
Kari E. Murros ${ }^{1 *}$, Vy A. Huynh ${ }^{2 \dagger}$, Timo M. Takala ${ }^{2}$ and Per E. J. Saris ${ }^{2 *}$ \\ ${ }^{1}$ Neurological Outpatient Clinic of Terveystalo Healthcare, Helsinki, Finland, 2 Department of Microbiology, Faculty of \\ Agriculture and Forestry, University of Helsinki, Helsinki, Finland
}

Parkinson's disease (PD) is the most prevalent movement disorder known and predominantly affects the elderly. It is a progressive neurodegenerative disease wherein $\alpha$-synuclein, a neuronal protein, aggregates to form toxic structures in nerve cells. The cause of Parkinson's disease (PD) remains unknown. Intestinal dysfunction and changes in the gut microbiota, common symptoms of $\mathrm{PD}$, are evidently linked to the pathogenesis of PD. Although a multitude of studies have investigated microbial etiologies of PD, the microbial role in disease progression remains unclear. Here, we show that Gram-negative sulfate-reducing bacteria of the genus Desulfovibrio may play a potential role in the development of PD. Conventional and quantitative real-time PCR analysis of feces from twenty PD patients and twenty healthy controls revealed that all PD patients harbored Desulfovibrio bacteria in their gut microbiota and these bacteria were present at higher levels in PD patients than in healthy controls. Additionally, the concentration of Desulfovibrio species correlated with the severity of PD. Desulfovibrio bacteria produce hydrogen sulfide and lipopolysaccharide, and several strains synthesize magnetite, all of which likely induce the oligomerization and aggregation of $\alpha$-synuclein protein. The substances originating from Desulfovibrio bacteria likely take part in pathogenesis of PD. These findings may open new avenues for the treatment of PD and the identification of people at risk for developing PD.

Keywords: hydrogen sulfide, magnetite, alpha-synuclein ( $\alpha$-Syn), gut Desulfovibrio bacteria, Parkinson's disease (PD)

\section{INTRODUCTION}

In Parkinson's disease (PD), intestinal symptoms such as constipation often precede the appearance of motor symptoms, suggesting that an etiological agent may be present in the intestine. Based on neuropathological findings, Braak and colleagues proposed in 2003 that PD is caused by an intestinal pathogen capable of passing through the gut mucosal barrier and traveling through enteric neurons before finally entering the central nervous system via the vagus nerve (Braak et al., 2003). In support of this view, Lewy bodies and Lewy neurites containing phosphorylated $\alpha$-synuclein protein $(\alpha-S y n)$, the classic neuropathological hallmarks of PD, can be found in both the central nervous system and the 
enteric nervous system (Barrenschee et al., 2017). Additionally, injected forms of $\alpha$-Syn are transported to the lower brainstem via the vagus nerve in rats (Holmqvist et al., 2014). It is proposed that the production of toxins and metabolites by gut microbes play a critical role in the pathogenesis of PD and that gut enteroendocrine cells serve as sites for the initial emergence of pathologic $\alpha$-Syn (Chandra et al., 2017).

Since 2015, changes in gut microbiota compositions in PD have been found in several large-scale case-control studies (Scheperjans et al., 2015; Shen et al., 2021). Composition changes concerning the phylum level are difficult to establish due to high variability in the relative abundances of bacterial phyla in PD studies (Chiang and Lin, 2019). Concerning the family level of bacteria, a recent meta-analysis on fourteen case-control studies showed, by $95 \%$ confidence interval analysis, significantly increased relative abundances of Verrucomicrobiaceae, Bifidobacteriaceae, and Christesenellaceae in PD gut microbiota (Shen et al., 2021). At the genus level, opportunistic pathogens including Porphyromonas, Prevotella and Corynebacterium were found to be elevated in PD in a microbiome-wide association study (Wallen et al., 2020). A limitation of these studies is that assessing relative changes in microbiota composition, rather than absolute quantitative changes, limits the chances of identifying diseaseassociated ecosystem configurations (Vandeputte et al., 2017; Boertien et al., 2019; Haikal et al., 2019). In this respect, the dynamics of Desulfovibrio bacteria (DSV) are not fully captured by studies focusing on the relative bacterial changes in PD gut microbiota. One case-control study offered a broad indication of $D S V$ dynamics, finding that the relative abundance of bacteria in the Desulfovibrionaceae family was elevated in PD patient microbiota (Lin et al., 2018). DSV have several interesting characteristics that lend themselves toward a potential role in PD pathogenesis and warrant further investigation. DSV are sulfate-reducing bacteria (SRB), commonly found in the environment and the human intestine with the potential to cause infections in humans (Loubinoux et al., 2002; Goldstein et al., 2003). As such, DSV produce hydrogen sulfide $\left(\mathrm{H}_{2} \mathrm{~S}\right)$, a metabolite known to influence cell signaling in neuronal cells at low concentrations and pose serious toxicity at higher concentrations (Carbonero et al., 2012; Panthi et al., 2018; Haouzi et al., 2020). $\mathrm{H}_{2} \mathrm{~S}$ has been observed to release mitochondrial cytochrome $\mathrm{c}$ into the cytosol, where the cytochrome is able to form $\alpha$-Syn radicals and thereby initiate $\alpha$-Syn oligomerization (Guo et al., 2015; Kumar et al., 2016). Further, $\mathrm{H}_{2} \mathrm{~S}$ can interfere with iron metabolism by increasing iron levels in the cytosol (Cassanelli and Moulis, 2001; Hälldin and Land, 2008), an event potentially inducing $\alpha$ Syn aggregate formations (Joppe et al., 2019). DSV have been found to colonize the mucus gel layer of the colon (Nava et al., 2012; Earley et al., 2015). Therefore, the $\alpha$-Syn-expressing enteroendocrine cells located in the gut wall, in close proximity to intestinal $D S V$, may be especially vulnerable to the toxic effects of $\mathrm{H}_{2} \mathrm{~S}$ and serve as a seeding point for $\alpha$-Syn aggregation in the nervous system. Additionally, $D S V$ have the ability to reduce ferric iron to ferrous iron by employing a periplasmic [FeFe]hydrogenase enzyme, present in practically all $D S V$, conferring the ability to produce magnetite $\left(\mathrm{Fe}_{3} \mathrm{O}_{4}\right)$ (Chistyakova et al., 2004; Park et al., 2008; Pereira et al., 2011). Uncoated magnetite nanoparticles have been reported to accelerate $\alpha$-Syn aggregation and are considered to be involved in $\mathrm{PD}$ pathogenesis (Joshi et al., 2015; Murros et al., 2019). As DSV are found in the gut microbiota of humans and are capable of producing extracellular magnetite and $\mathrm{H}_{2} \mathrm{~S}$, both of which induce oligomerization and aggregation of $\alpha$-Syn, it is rational to suspect that there may be a correlation between these bacteria and PD. Here, we employed a targeted PCR-based approach to determine absolute quantitative changes in the levels of DSV bacteria between PD patients and healthy controls.

\section{MATERIALS AND METHODS}

\section{Research Subjects, Sample Collection, and Ethical Issues}

The study participants consisted of 20 PD patients and 20 healthy controls. PD patient were recruited from the patient material of the Neurology Outpatient Clinic of Terveystalo Healthcare, Kamppi, Helsinki. The control group consisted of 10 spouses and 10 nonspouses of PD patients. As a prerequisite, selected PD patients had to fulfill the clinical features of the UK Parkinson's Disease Society Brain Bank diagnostic criteria (Hughes et al., 1992). Furthermore, PD patient disease progression was scored using the Hoehn and Yahr scale as an estimate of the clinical stage of PD (Hoehn and Yahr, 1967). Symptoms or signs of parkinsonism were exclusion criteria for the controls. Exclusion criteria for both groups included cognitive disturbance (Mini-Mental State Examination points $<25$ ) and a history of antibiotic use within 3 months prior to the date of fecal sampling. Fecal samples were collected by donors in sealed polypropylene containers and subsequently frozen and stored at $-75^{\circ} \mathrm{C}$ until further analyses. The study was approved by the Ethics Committee of Helsinki and the Uusimaa Health District area of Finland, and all procedures were in accordance with the relevant regulations. Each study participant also provided written informed consent.

\section{Bacterial Strains and Culture Conditions}

Two collection strains, D. desulfuricans MB (DSM 6949) and D. vulgaris DSM 644, were obtained from the Leibniz Institute DSMZ-German Collection of Microorganisms and Cell Cultures, Braunschweig, Germany. Liquid Postgate medium (DSMZ medium 63) for bacterial culture was made anoxic by sparging with nitrogen gas for 1 hour at $80^{\circ} \mathrm{C}$ prior to autoclavation. The medium was aliquoted into Hungate-type tubes and bacterial inoculation was performed in an anaerobic workstation (Don Whitley Scientific, West Yorkshire, UK). The bacteria were cultured anaerobically at $37^{\circ} \mathrm{C}$. Anaerobic conditions inside the anaerobic jar were maintained using the Microbiology Anaerocult $^{\circledR}$ A system (Merck KGaA, Darmstadt, Germany) and indicated by an Anaerotest ${ }^{\circledR}$ strip (Merck KgaA). Ferrous sulfide (black precipitate) formation after two to seven days was used as an indicator for bacterial growth. 


\section{DNA Techniques}

DNA from the fecal samples was extracted using the Stool DNA Isolation Kit (Norgen Biotek, Ontario, Canada). The bacterial DNA of D. desulfuricans MB (DSM 6949) and D. vulgaris DSM 644, for use as positive controls, were isolated using the MagAttract HMW DNA Kit (Qiagen GmbH, Hilden, Germany). PCR products were purified using the SanPrep Column PCR Product Purification kit (BBI Life Sciences, Shanghai, China). Gel electrophoresis was performed in $0.9 \%$ or $1.5 \%(\mathrm{w} / \mathrm{v})$ agarose gel containing $0.1 \mu \mathrm{g} / \mathrm{ml}$ ethidium bromide, followed by visualization under UV light. The size markers used were $100 \mathrm{bp}$ GeneRuler DNA ladder or $1 \mathrm{~kb}$ GeneRuler DNA ladder (Thermo Fisher Scientific, Waltham, MA, USA).

\section{Primers and PCR Conditions}

A pair of universal primers targeting the bacterial 16S rRNA gene were used to validate the success of DNA isolation from fecal samples. Primers for detecting periplasmic [FeFe]- hydrogenase gene were designed by multiple sequence alignment of the periplasmic $[\mathrm{FeFe}]-$ hydrogenase large subunit (hydA) genes of different Desulfovibrio spp. The primer specificity was analyzed using the Primer-BLAST webtool by NCBI (https://www.ncbi.nlm. nih.gov/tools/primer-blast/). The $16 \mathrm{~S}$ rRNA gene primer sequences used for specific detection of the Desulfovibrio genus and species including Desulfovibrio desulfuricans, D. fairfieldensis, D. piger, and D. vulgaris were obtained from previous studies. All primers used in this study are listed in Table $\mathbf{1}$.

A standard PCR procedure was followed in both conventional and quantitative PCR according to the manufacturer's protocol for Phusion High-Fidelity DNA polymerase (Thermo Fisher Scientific). Specifically, each $20 \mu$ reaction comprised of $1 \times$ Phusion HF buffer (Thermo Fisher Scientific), $0.2 \mathrm{mM}$ dNTP mix (Thermo Fisher Scientific), $0.5 \mu \mathrm{M}$ of each primer, $1 \mathrm{U}$ of Phusion High-Fidelity DNA polymerase (Thermo Fisher Scientific), and DNA. The thermal cycle was set as follows: $98^{\circ} \mathrm{C}$ for 30 secs followed by $30-40$ cycles of denaturing at $98^{\circ} \mathrm{C}$ for 10 secs, annealing at $55-62^{\circ} \mathrm{C}$, depending on the primers used, for 10 secs and elongation at $72^{\circ} \mathrm{C}$ for 20 secs, continuing with $72^{\circ} \mathrm{C}$ for $5 \mathrm{~min}$ and final $4^{\circ} \mathrm{C}$ for $15 \mathrm{~min}$. Reaction mixtures contained approximately $170 \mathrm{ng}$ of total DNA extracted from fecal samples or 20 ng of bacterial genomic DNA or water as negative control.

The PCR products were checked by gel electrophoresis, purified, and sequenced (Institute of Biotechnology, University of Helsinki, Finland), followed by comparison to the NCBI GenBank database for analysis.

\section{Cloning of 16S rRNA and hydA Gene PCR Products}

Vector pHelix1 (Roche Diagnostics GmbH, Mannheim, Germany) was amplified with the primers AmpF and OriR to obtain an amplicon containing only the ampicillin resistance gene and the origin of replication $\left(a m p^{R}\right.$-ori). The amplicons were purified and checked by gel electrophoresis.

The purified PCR products of the 16S rRNA gene of the four $D S V$ species and the hydA amplicons of $D$. desulfuricans $\mathrm{MB}$, after being verified by sequencing, were phosphorylated with T4 Polynucleotide Kinase (Thermo Scientific) and ligated with the $a m p^{R}$-ori fragment using T4 DNA ligase (Thermo Scientific). The ligation mixtures were introduced into competent $E$. coli XL1-Blue cells (Agilent Technologies, Santa Clara, CA, USA) by electroporation with pulse $2.5 \mathrm{kV}, 200 \Omega$ and $25 \mu \mathrm{FD}$ (Zabarovsky and Winberg, 1990). The transformed cells were plated on LB agar plates containing $100 \mu \mathrm{g} / \mathrm{ml}$ ampicillin. Plasmids were isolated using a SanPrep Column Plasmid Mini-

TABLE 1 | Primers used in the study.

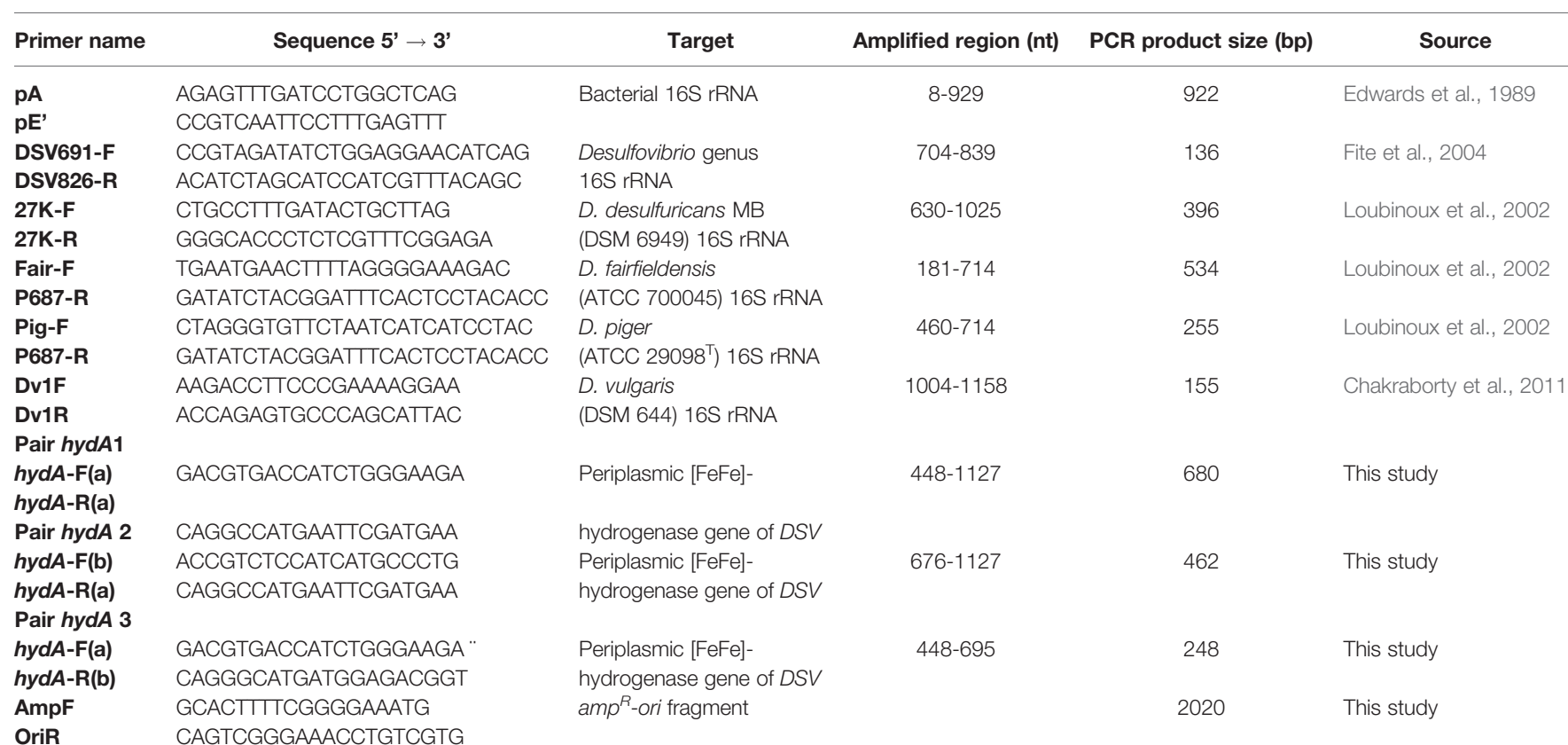


preps kit (BBI Life Sciences), and the correct constructs were confirmed by PCR with corresponding insert primers and gel electrophoresis. Plasmids with correct inserts were used as standards in quantitative real-time PCR.

\section{Quantitative Real-Time PCR (qPCR)}

Samples which were deemed to contain both $D S V$ and hydA were selected for bacterial quantification using a QuantStudio 3 RealTime PCR System (Thermo Fisher Scientific). SYBR ${ }^{\mathrm{TM}}$ Green I (FMC BioProducts, Rockland, ME, USA) at a final concentration of $0.1 \times$ was used as a fluorescent dye. Constructed plasmids carrying 16S rRNA or hydA fragments were used as standards. Reaction mixtures contained approximately $70 \mathrm{ng}$ of total DNA extracted from fecal samples or standards with final amount ranging from $2 \times 10^{3}$ to $2 \times 10^{7}$ copies. Reaction mixtures containing $70 \mathrm{ng}$ of extracted DNA from $D S V$-bacterianegative healthy controls stool were also created and used to construct standard curves. Reactions containing sterile Milli-Q water instead of DNA were used as negative controls. Each PCR reaction was performed in technical triplicates. The specificity of the amplification was assessed by melt curve analysis. Gel electrophoresis was performed to confirm these predictions.

\section{Statistical Analysis}

IBM SPSS Statistics 20 software was used to analyze the results. A Fisher's exact test was used to examine the association between the presence of $D S V$ bacteria or the $D S V$-specific hydA gene and Parkinson's disease. The strength of the association was analyzed by Phi and Cramer's V test with an outcome value greater than 0.25 indicating a strong relationship. A Mann-Whitney $U$ test was used to compare DSV quantities between PD patients and healthy controls, as well as between patients with high and low levels of disease progression. The significance threshold was set at 0.05 . All tests were two-sided.

\section{RESULTS}

\section{Basic Characteristics of Study Participants}

The PD group was well-matched with the control group with regard to age, gender, and body mass index. Fifteen PD patients presented with idiopathic hyposmia, and fourteen patients suffered from chronic constipation (fewer than three bowel movements a week) in contrast to none in the control group (Table 2).

\section{Association of Desulfovibrio spp., hydA, and Parkinson's Disease}

In order to establish a relationship between the presence of Desulfovibrio spp. in the human intestinal tract and the development of PD, we performed conventional PCR to specifically detect $D S V$ within fecal samples obtained from $\mathrm{PD}$ patients and healthy controls. All PCR products from control laboratory strains and fecal samples were tested for target specificity by gel electrophoresis and subsequent sequencing. By sequencing, it was confirmed that the species-level primers specific to $D$. desulfuricans, D. fairfieldensis, D. piger, and D. vulgaris showed high specificity, as they amplified 16S rRNA fragments of expected sizes only from the corresponding bacterial species. The genus-level primers to detect Desulfovibrio also amplified fragments of correct sizes from the fecal samples, but some amplicons were later determined to not be Desulfovibrio DNA by sequencing. Thus, as the genus-level primers were not specific, they were excluded from subsequent experiments.

In total, sixteen PD patients (80\%) and eight healthy controls (40\%) were positive with species specific DSV PCR (Table 3). Some samples from healthy controls were detected with more than one species of $D S V$. In PD patients, $D$. desulfuricans, $D$. fairfieldensis, and D. piger were found, whereas for the healthy controls group, all four examined species were detected (Table 3). Statistical analysis revealed a strong association between the presence of DSV and PD $(P=0.022$, Fisher's exact test, Phi value $=0.408)$. Due to the non-specificity of the genus-level $16 \mathrm{~S}$ rRNA primers, three additional primer pairs targeting the $D S V$ specific [FeFe]- hydrogenase (hydA) gene were designed and tested as a proxy for detecting a wider range of DSV species, as well as an indicator of putative magnetite production in participants' microbiota. Sequencing of the obtained test-PCR products showed that only hydA-primer pair 1 specifically amplified $D S V$-hydA fragments of correct sizes, and thus those primers were selected for further experiments. As a result, hydA was detected in fecal samples from all 20 PD patients (100\%) and

TABLE 2 | Clinical characteristics of patients and controls.

\begin{tabular}{|c|c|c|}
\hline & Patients $(n=20)$ & Controls $(n=20)$ \\
\hline Age in years, median (range) & $70.0(58-80)$ & $68.5(54-79)$ \\
\hline Gender, male (\%) & 60 & 40 \\
\hline Body Mass Index, kg/m², median (range) & $25.0(18.3-33.0)$ & $23.5(18.4-29.4)$ \\
\hline Years from PD diagnosis, median (range) & $10(2-26)$ & - \\
\hline Hoehn \& Yahr stage > 2, prevalence (\%) & 55 & - \\
\hline Daily levodopa dose (mg), median (range) & $525(200-1100)$ & - \\
\hline Dopamine agonist users (\%) & 70 & - \\
\hline Probiotic users (\%) & 10 & 5 \\
\hline Hypertensive, on medication (\%) & 25 & 20 \\
\hline Idiopathic hyposmia, prevalence (\%) & 75 & 0 \\
\hline Constipation, prevalence (\%) & 70 & 0 \\
\hline Current smokers (\%) & 0 & 0 \\
\hline
\end{tabular}


TABLE 3 | Summary of the PCR detection and quantification of Desulfovibrio spp. from patients and healthy individuals.

\begin{tabular}{|c|c|c|c|c|c|c|c|}
\hline \multicolumn{4}{|c|}{ Parkinson's group $(n=20)$} & \multicolumn{4}{|c|}{ Control group $(n=20)$} \\
\hline Gender & $\begin{array}{c}\text { DSV species detected by } \\
\text { PCR }\end{array}$ & $\begin{array}{c}D S V \text { quantity (bacteria/g } \\
\text { feces) }\end{array}$ & hydA & Gender & DSV species detected by PCR & $\begin{array}{c}\text { DSV quantity (bacteria/g } \\
\text { feces) }\end{array}$ & hydA \\
\hline$M^{*}$ & D. piger & $3.3 \times 10^{7}$ & + & M & D. fairfieldensis & $1.9 \times 10^{6}$ & + \\
\hline$M^{*}$ & D. fairfieldensis & $2.6 \times 10^{7}$ & + & M & D. fairfieldensis & $1.0 \times 10^{6}$ & + \\
\hline$M^{*}$ & D. fairfieldensis & $2.6 \times 10^{7}$ & + & $\mathrm{M}$ & D. fairfieldensis & $5.6 \times 10^{5}$ & + \\
\hline$M^{*}$ & D. fairfieldensis & $1.6 \times 10^{7}$ & + & $\mathrm{F}$ & D. desulfuricans & $1.9 \times 10^{5}$ & + \\
\hline$M^{*}$ & D. desulfuricans & $7.3 \times 10^{6}$ & + & $\mathrm{M}$ & D. desulfuricans, D. vulgaris & $7.8 \times 10^{4}$ & + \\
\hline$F^{\star}$ & D. fairfieldensis & $4.2 \times 10^{6}$ & + & $\mathrm{F}$ & D. desulfuricans & $5.1 \times 10^{4}$ & + \\
\hline$M^{*}$ & D. piger & $2.2 \times 10^{6}$ & + & $\mathrm{M}$ & $\begin{array}{l}\text { D. desulfuricans, D. fairfieldensis, D. piger, } \\
\text { D. vulgaris }\end{array}$ & $2.6 \times 10^{4}$ & + \\
\hline $\mathrm{F}$ & D. desulfuricans & $1.2 \times 10^{4}$ & + & $\mathrm{M}$ & D. piger & $1.3 \times 10^{4}$ & + \\
\hline M & D. desulfuricans & $4.4 \times 10^{3}$ & + & $\mathrm{M}$ & None & & + \\
\hline $\mathrm{F}$ & D. desulfuricans & $4.1 \times 10^{3}$ & + & $\mathrm{F}$ & None & & + \\
\hline $\mathrm{F}^{\star}$ & D. desulfuricans & $2.1 \times 10^{3}$ & + & $\mathrm{F}$ & None & & + \\
\hline $\mathrm{F}^{\star}$ & D. desulfuricans & $<2.0 \times 10^{3}$ & + & $M$ & None & & + \\
\hline $\mathrm{F}^{\star}$ & D. desulfuricans & $<2.0 \times 10^{3}$ & + & $\mathrm{F}$ & None & & + \\
\hline$M^{*}$ & D. desulfuricans & $<2.0 \times 10^{3}$ & + & $M$ & None & & None \\
\hline $\mathrm{F}$ & D. desulfuricans & $<2.0 \times 10^{3}$ & + & $\mathrm{F}$ & None & & None \\
\hline M & D. desulfuricans & $<2.0 \times 10^{3}$ & + & $\mathrm{F}$ & None & & None \\
\hline$M$ & None & & + & $\mathrm{M}$ & None & & None \\
\hline$M$ & None & & + & $\mathrm{F}$ & None & & None \\
\hline$M$ & None & & + & $\mathrm{F}$ & None & & None \\
\hline $\mathrm{F}$ & None & & + & $\mathrm{M}$ & None & & None \\
\hline
\end{tabular}

The cases are displayed by decreasing DSV quantities. M, male; F, female. Asterisks indicate patients with level of disability exceeded 2.0 points based on Hoehn-Yahr classification.

13 healthy controls (65\%).The PCR results were confirmed by sequencing. In comparison to the results from strain/speciesspecific primers, an additional four patients and five healthy controls were determined to possess $D S V$ bacteria with the hydA-specific primers. The presence of the $D S V$-specific [FeFe]hydrogenase gene was strongly correlated with PD $(P=0.008$, Fisher's exact test, Phi value $=0.461$ ).

\section{Quantity of DSV Bacteria in Human Feces and Parkinson's Disease}

To assess whether there is a difference in $D S V$ quantity between healthy controls and PD patients, quantitative real-time PCR was carried out to determine the bacterial amount in the DSV-and hydA-positive fecal samples from both groups. Standard curves were constructed for every PCR reaction using serial dilutions of the constructed standard plasmids with known copy numbers. The qPCR products were checked by gel electrophoresis. The results revealed that $\mathrm{PD}$ patients had significantly higher amounts of $D S V$ in their feces than healthy controls $(P=$ 0.044, Mann-Whitney U-test). Although most PD patients had relatively low levels of $D S V\left(<10^{5}\right.$ bacteria/g feces), the quantity reached to as high as $3.3 \times 10^{7}$ bacteria/g feces. In the healthy controls group, the maximum $D S V$ level was approximately $1.9 \times 10^{6}$ bacteria/g feces (Table 3 ).

In addition, we examined whether the amount of $D S V$ present in PD patient fecal samples correlated with the severity of the disease. The level of disability exceeded 2.0 points in 11 patients based on the Hoehn-Yahr classification system. Notably, all seven patients with $D S V$ loads higher than any of the healthy controls belonged to this category. Furthermore, the eleven patients with a more severe disability of PD had a significantly higher amount of $D S V$ bacteria than the nine patients that were classified below 2.0 points under the Hoehn-Yahr system $(P=$ 0.009 , Mann-Whitney U-test). We also investigated the DSV levels between subjects experiencing constipation $(n=14)$ and not experiencing constipation $(n=26)$. The statistical result suggested that the $D S V$ amount was significantly higher in the group suffering from constipation ( $P=0.036$, Mann-Whitney U-test). As idiopathic hyposmia was very prevalent among PD patients, Mann-Whitney U test was performed to compare DSV quantity between individuals who suffered from hyposmia $(n=15)$ and those who did not $(n=25)$. Statistically, $D S V$ bacteria were significantly more abundant in patients with hyposmia $(P=0.009)$.

\section{DISCUSSION}

Our results established a significant correlation between DSV bacteria and PD. The quantity of $D S V$ bacteria in fecal samples correlated with the severity of the disease, and higher amounts of $D S V$ were found in PD samples compared to control samples. All fecal samples of PD patients were positive for the $D S V$-specific [FeFe]-hydrogenase gene. DSV bacteria, D. desulfuricans, $D$. fairfieldensis, and D. piger, were significantly more common in PD samples than in control samples. Previous attempts to correlate DSV abundance with different intestinal diseases have failed to show correlations (Zinkevich and Beech, 2000; Fite et al., 2004; Scanlan et al., 2009). In our study, all PD patients harbored $D S V$, but as the primers used for hydA detection were not suitable for qPCR (results not shown), we cannot exclude the possibility that the patients with low levels of the four examined $D S V$ species may have high levels of other DSV species. As $20 \%$ of the PD patients had unknown DSV species, these bacteria 
must be isolated and characterized to enable the development of primers suitable for qPCR. Together, the data strongly suggests that $D S V$ play a role in the pathogenesis of $\mathrm{PD}$.

$D S V$ have an ability to bind to human colonic mucin, and they are found at high levels (approximately $10^{4}$ to $10^{6}$ bacteria/g feces) in mucosal samples of the large intestine (Zinkevich and Beech, 2000; Nava et al., 2012; Earley et al., 2015). An important characteristic of $D S V$ is its ability to perform dissimilatory sulfate reduction by utilizing sulfate as an electron acceptor for respiration, thereby producing hydrogen sulfide $\left(\mathrm{H}_{2} \mathrm{~S}\right)$ (Carbonero et al., 2012). $\mathrm{H}_{2} \mathrm{~S}$ can also be produced from cysteine degradation catalyzed by L-cysteine desulfhydrase, present in intestinal pathogens such as Salmonella Typhimurium, Helicobacter pylori, Escherichia coli and in pathogens belonging to genera of DSV, Clostridium, Enterobacter, Klebsiella and Streptococcus. Additionally, Bilophila wadsworthia and $D$. desulfuricans can produce $\mathrm{H}_{2} \mathrm{~S}$ through a third pathway as a byproduct of taurine catabolism (Carbonero et al., 2012).

$\mathrm{H}_{2} \mathrm{~S}$ displays Janus-faced characteristics by carrying physiologic signaling events in neuronal cells and showing neuroprotective properties while also being highly toxic at high concentrations (Panthi et al., 2018; Haouzi et al., 2020). In humans, an acute low-dose $\mathrm{H}_{2} \mathrm{~S}$ gas exposition can cause eye irritation and olfactory dysfunction whereas a high-dose exposition can lead to severe central nervous system dysfunction and even death (Rumbeiha et al., 2016; Haouzi et al., 2020). As a diffusible gas that is more soluble than $\mathrm{CO}_{2}$ or $\mathrm{O}_{2}, \mathrm{H}_{2} \mathrm{~S}$ can enter the blood circulation from the gut (Tomasova et al., 2016; Haouzi et al., 2020). It is reasonable to assume that $\mathrm{H}_{2} \mathrm{~S}$ concentrations are raised in the gastrointestinal wall structures in cases where the gut harbors an increased amount of $\mathrm{H}_{2} \mathrm{~S}$-producing $\mathrm{DSV}$. Elevated $\mathrm{H}_{2} \mathrm{~S}$ concentrations in these structures may result in constipation due to the compound's ability to inhibit gastrointestinal motility (Singh and Lin, 2015). In the present study, the constipation prevalence among PD patients was as high as $70 \%$. Notably, constipation is a prevalent ailment in $\mathrm{PD}$ and it can precede the motor features of PD and form a risk for PD onset (Abbott et al., 2001; Lin et al., 2014; Stirpe et al., 2016). In one study, constipation was reported to associate with increased quantities of DSV, Cristensenellaceae and Firmicute bacteria in fecal samples of non-PD subjects (Jalanka et al., 2019). However, whether DSV species are a cause or a consequence of constipation in $\mathrm{PD}$ remains an unanswered question. Possibly, DSV species take part in the evolution of PD after their quantity exceeds a certain threshold level.

Hydrogen sulfide has been demonstrated to alter intracellular biochemistry to favor $\alpha$-Syn aggregation. Hydrogen sulfide can release iron from mammalian ferritin in cells and raise iron levels in the cytosolic labile iron pool (Cassanelli and Moulis, 2001; Hälldin and Land, 2008). The resultant effect on $\alpha$-Syn-expressing nerve cells is of concern as both ferric and ferrous iron are capable of inducing $\alpha$-Syn aggregates, the main neuropathologic feature of PD (Joppe et al., 2019). Overexpression of endogenously produced $\mathrm{H}_{2} \mathrm{~S}$ can also release mitochondrial cytochrome $\mathrm{c}$ into the cytosol, where this cytochrome has been observed to form $\alpha$-Syn radicals and subsequently induce $\alpha$-Syn oligomerization, an early stage in $\alpha$-Syn aggregation (Guo et al., 2015; Kumar et al., 2016; Li et al., 2019). The colonic mucosa is normally protected from $\mathrm{H}_{2} \mathrm{~S}$ by the sulfide oxidation pathway, including the enzymes sulfide quinone oxidoreductase, persulfide dioxygenase, rhodanese and sulfide oxidase (Picton et al., 2002; Ramasamy et al., 2006; Libiad et al., 2014). If DSV, the dominant SRB in the intestinal mucosa (Zinkevich and Beech, 2000; Nava et al., 2012; Earley et al., 2015), increase in number, $\mathrm{H}_{2} \mathrm{~S}$ will likely be produced at higher levels that may exceed the capacity of the detoxifying enzymes. In addition, inflammation decreases the detoxification capacity of the mucosal tissue, resulting in an increased level of $\mathrm{H}_{2} \mathrm{~S}$ (Flannigan et al., 2013). The observation that smoking induces a causally protective effect on PD occurrence lends support for the role of $\mathrm{H}_{2} \mathrm{~S}$ and its interaction with detoxifying enzymes in $\mathrm{PD}$ pathogenesis (Mappin-Kasirer et al., 2020). It is known that cyanide, present in variable amounts in cigarette smoke, reacts with $\mathrm{H}_{2} \mathrm{~S}$ under the influence of rhodanese to form thiocyanate, thus resulting in lowered $\mathrm{H}_{2} \mathrm{~S}$ levels (Picton et al., 2002).

The enteroendocrine cells of the gut, which display neuronlike properties and are connected to autonomous enteric nerves, express $\alpha$-Syn (Chandra et al., 2017). Anatomically, enteroendocrine cells extend their apical cytoplasmic processes towards the gut luminal surface. Thus, it is reasonable to argue that this feature will increase the $D S V$-borne $\mathrm{H}_{2} \mathrm{~S}$ exposure risk. In addition, overgrowth of $D S V$ may induce colonic mucosal barrier dysfunction by influencing the metabolism of butyrate, a short-chain fatty acid (SCFA), which has been reported to be the major energy substance for the colonic epithelium (Chapman, 2001). Overgrowth of $\mathrm{H}_{2} \mathrm{~S}$-producing bacteria such as $D S V$ poses an apparent threat to this barrier function, as sulfides impair the oxidation of butyrate (Babidge et al., 1998). In this context, it has been shown that PD patients exhibit increased intestinal permeability correlating with increased intestinal mucosa staining for $\alpha$-Syn (Forsyth et al., 2011). In addition, lipopolysaccharides produced by $D S V$ can apparently increase intestinal permeability and $\alpha$-Syn expression (Kelly et al., 2014; Fuke et al., 2019; Gorecki et al., 2019). Notably, the mucin layer of the colon consists primarily of glycoproteins, which carry sulfate residues, and degradation products of these sulfomucins serve as a source of sulfate for SRB such as DSV (Derrien et al., 2008). Further, Akkermansia muciniphila and Bifidobacterium, abundant inhabitants of the human gut, can degrade mucin (Derrien et al., 2008; RuasMadiedo et al., 2008). Several studies on gut microbiota in PD have shown increases in the relative abundance of these bacteria (Chiang and Lin, 2019; Shen et al., 2021). Bifidobacteria are commonly available as commercial products, and their abundance in the gut is reported to correlate to the levodopa dose in PD (Wallen et al., 2020). A. muciniphila, in addition to its ability to degrade mucin, seems to promote mucus thickness and stimulate mucus turnover rate, thus apparently freeing considerable amounts of sulfate for SRB (Zhou, 2017). Support for this interaction between A. muciniphila and SRB is provided 
by a study on the metabolome profile of PD patients wherein significant changes in sulfur metabolism, including $\mathrm{H}_{2} \mathrm{~S}$, were verified through computational modeling, and the observed changes were driven by $A$. muciniphila and B. wadsworthia (Hertel et al., 2019). As a pathogenetic model, it is justifiable to propose that excessive production of $\mathrm{H}_{2} \mathrm{~S}$ by gut $D S V$, cross-fed by $A$. muciniphila, leads to $\alpha$-Syn oligomerization and aggregation in the adjacent enteroendocrine cells. From there, $\alpha$-Syn oligomers may make their way to the brain via the vagus nerve. This proposed model agrees with the initial proposal by Braak and colleagues that PD is caused by a pathogen capable of passing through the mucosal barrier of the gastrointestinal tract (Braak et al., 2003). Routes other than the vagal route for $\alpha$-Syn oligomer transport come into consideration as well. Elevated levels of oligomeric $\alpha$-Syn have been detected in plasma samples of PD patients, and it has been documented that $\alpha$ Syn can cross the blood brain barrier (BBB) in both the bloodto-brain and brain-to-blood direction (El-Agnaf et al., 2006; Sui et al., 2014). If $D S V$-produced $\mathrm{H}_{2} \mathrm{~S}$ plays a central role in the pathogenesis of $\mathrm{PD}$, it is reasonable to presume that, in addition to $D S V$, other $\mathrm{H}_{2} \mathrm{~S}$-producing bacteria, such as $H$. pylori and Clostridium species, may also induce PD (Murros, 2021). In fact, people with PD have an increased prevalence of $H$. pylori infections, and eradication of this pathogen has been reported to improve motor functions in PD patients (McGee et al., 2018). Recently, a population-based cohort showed that Clostridium difficile infections temporarily elevate the risk of PD (Kang et al., 2020). Although increased production of $\mathrm{H}_{2} \mathrm{~S}$ may play a pivotal role in $\mathrm{PD}$ pathogenesis, inflammation caused by $D S V$ and other infective agents like curli-producing E. coli and Proteus mirabilis evidently play a role as well (Chen et al., 2016; Choi et al., 2018). Experimentally, an exposure to bacteria that produce the curli protein results in $\alpha$-Syn depositions in both the gut and the brain (Chen et al., 2016). Furthermore, it has been shown that LPS can accelerate the synthesis of curli fibrils (Swasthi and Mukhopadhyay, 2017). After a primary inflammatory event, a sustained low-level inflammation may develop, resulting in increased intestinal permeability, leakage of inflammatory agents, and ultimately a chronic systemic immune response that may weaken the BBB (Houser and Tansey, 2017).

The potential capability of $D S V$ to produce magnetite $\left(\mathrm{Fe}_{3} \mathrm{O}_{4}\right)$ deserves special attention, as uncoated magnetite nanoparticles can accelerate $\alpha$-Syn aggregation (Joshi et al., 2015). Most of the $D S V$ contain a [FeFe]-hydrogenase metalloenzyme system, which catalyzes both the oxidation and reduction of molecular hydrogen and protons, respectively (Pereira et al., 2011). Based on studies on $D$. vulgaris, it has been suggested that the reduction of soluble ferric iron to ferrous iron is a periplasmic process that requires the presence of a [FeFe]-hydrogenase (Park et al., 2008). An interaction between ferrous iron and amorphous ferric hydroxide can result in magnetite formation, and it has been shown that magnetite can be formed from amorphous ferric hydroxide in the presence of iron- and sulfate-reducing bacteria (Chistyakova et al., 2004; Lenders et al., 2016). D. desulfuricans has the ability to synthesize magnetite (Lovley et al., 1993), and this DSV species was the most frequently found $D S V$ species in the patients included in this study. Notably, magnetite production in anaerobic condition by dissimilatory ironreducing bacteria is coupled with energy-metabolism and the produced magnetite is extracellular (Konhauser, 1997). Magnetite nanoparticles can be absorbed into intestinal cells and blood circulation by endocytosis (Fröhlich and Roblegg, 2012; Bergin and Witzmann, 2013). In a study on skin samples of patients having $\mathrm{PD}$, low-temperature magnetometric measurements revealed apparent superparamagnetic magnetite particles in the dermal layer of several PD patients, and it was proposed that these particles were probably gutborne and produced by DSV (Murros et al., 2019). Support for the ability of magnetite to accumulate in the brain is provided by a study on 822 brain specimens sampled from seven human cadaver brains (Gilder et al., 2018). However, the possible connection between bacterial magnetite nanoparticles and PD pathogenesis is still speculative; magnetometric data from stool samples and biopsy specimens from the colon and brain of PD patients are currently unavailable.

In the present study, specific $D S V$ species were identified in most of the fecal samples of PD, with the quantities of DSV correlating with the PD severity. In addition, the $D S V$-specific $[\mathrm{FeFe}]$ - hydrogenase gene was found in all PD samples indicating an existence of other unidentified DSV species. These findings suggest that $D S V$ may be an etiological agent promoting microbiome-related PD pathogenesis. We present the following pathogenetic model. First, DSV colonize the intestine permanently, increase in numbers and produce hydrogen sulfide in amounts exceeding the $\mathrm{H}_{2} \mathrm{~S}$ detoxification capacity of the mucosal sulfide oxidation pathway (especially the ratelimiting sulfide quinone oxidoreductase), while also producing LPS and magnetite (in at least some DSV species) near the enteroendocrine cells. These agents subsequently induce $\alpha$-Syn oligomerization and aggregation in the intestinal enteroendocrine cells. Secondly, toxic $\alpha$-Syn oligomers spread in a prion-like manner, traveling from enteroendocrine cells to the brain mainly via the vagal nerve and possibly via the bloodstream, where they ultimately cause damage to the brain dopaminergic system. In addition, magnetite nanoparticles produced by $D S V$ may pass into the bloodstream from the intestine, cross the BBB, and accelerate $\alpha$-Syn aggregation in the brain. This proposed model should be further evaluated in future research. Future studies could, in the prevention and treatment of $\mathrm{PD}$, focus on developing methods to eradicate $D S V$ from the human intestine by antibiotics, phage therapy, fecal transplantation, diet changes, or a combination of these interventions. Isolation of $D S V$ from the human intestine is critical, as it allows for designing better primers, antibiotic profiling and phagotype screening. Isolation of these bacteria also enables genome sequencing of PD-associated DSV and genomic comparison to environmental and healthy-carrier isolates of $D S V$, potentially aiding in the identification of therapeutic targets among the gene products specific to $\mathrm{PD}$ associated $D S V$. 


\section{ADDITIONAL INFORMATION}

Correspondence and requests for materials should be addressed to Kari Murros and Per Saris.

\section{DATA AVAILABILITY STATEMENT}

The raw data supporting the conclusions of this article will be made available by the authors, without undue reservation.

\section{ETHICS STATEMENT}

The studies involving human participants were reviewed and approved by Ethics Committee of Helsinki and the Uusimaa Health District area of Finland ("Desulfovibrios in Parkinson's disease"-protocol was accepted on 27th of May 2019 under the registration number/code HUS/975/22019 and "Occurrence of Desulfovibrio bacteria specific Fe-Fe-hydrogenase gene in feces of patients with Parkinson's disease" was accepted on 5th of Sept 2019 under the code HUS/2248/2019). The patients/participants

\section{REFERENCES}

Abbott, R., Petrovich, H., White, L. R., Masaki, K. H., Tanner, C. M., Curb, J. D., et al. (2001). Frequency of Bowel Movements and the Future Risk of Parkinson's Disease. Neurology 57, 456-462. doi: 10.1212/wnl.573.456

Babidge, W., Millard, S., and Roediger, W. (1998). Sulfides Impair Short Chain Fatty Acid $\beta$-Oxidation At acyl-CoA Dehydrogenase Level in Colonocytes: Implications for Ulcerative Colitis. Mol. Cell. Biochem. 181 (1), 117-124. doi: 10.1023/A:1006838231432

Barrenschee, M., Zorenkov, D., Böttner, M., Lange, C., Cossais, F., Scharf, A. B., et al. (2017). Distinct Pattern of Enteric Phospho-Alpha-Synuclein Aggregates and Gene Expression Profiles in Patients With Parkinson's Disease. Acta Neuropathol. Commun. 5 (1), 1-1. doi: 10.1186/s40478-016-0408-2

Bergin, I. L., and Witzmann, F. A. (2013). Nanoparticle Toxicity by the Gastrointestinal Route: Evidence and Knowledge Gaps. Int. J. Biomed. Nanosci. Nanotechnol. 3 (12), 10.1504/IJBNN.2013.054515. doi: 10.1504/ijbnn.2013.054515

Boertien, J. M., Pereira, P. A. B., Aho, V. T. E., and Scheperjans, F. (2019). Increasing Comparability and Utility of Gut Microbiome Studies in Parkinson's Disease: A Systematic Review. J. Parkinsons. Dis. 9 (s2), S297s312. doi: $10.3233 /$ jpd-191711

Braak, H., Rüb, U., Gai, W. P., and Del Tredici, K. (2003). Idiopathic Parkinson's Disease: Possible Routes by Which Vulnerable Neuronal Types may be Subject to Neuroinvasion by an Unknown Pathogen. J. Neural Transm. (Vienna) 110 (5), 517-536. doi: 10.1007/s00702-002-0808-2

Carbonero, F., Benefiel, A. C., Alizadeh-Ghamsari, A. H., and Gaskins, H. R. (2012). Microbial Pathways in Colonic Sulfur Metabolism and Links With Health and Disease. Front. Physiol. 3:448. doi: 10.3389/fphys.2012.00448

Cassanelli, S., and Moulis, J. (2001). Sulfide is an Efficient Iron Releasing Agent for Mammalian Ferritins. Biochim. Biophys. Acta 1547 (1), 174-182. doi: 10.1016/ s0167-4838(01)00182-0

Chakraborty, R., Hazen, T. C., Joyner, D. C., Küsel, K., Singer, M. E., Sitte, J., et al. (2011). Use of Immunomagnetic Separation for the Detection of Desulfovibrio Vulgaris From Environmental Samples. J. Microbiol. Methods 86 (2), 204-209. doi: 10.1016/j.mimet.2011.05.005

Chandra, R., Hiniker, A., Kuo, Y. M., Nussbaum, R. L., and Liddle, R. A. (2017). $\alpha-$ Synuclein in Gut Endocrine Cells and its Implications for Parkinson's Disease. JCI Insight 2 (12), e92295. doi: 10.1172/jci.insight.92295 provided their written informed consent to participate in this study.

\section{AUTHOR CONTRIBUTIONS}

$\mathrm{KM}$ and $\mathrm{VH}$ contributed equally to the work of this study. KM conceived the idea of the PD-DSV connection and performed the clinical studies. PS and $\mathrm{VH}$ conceived the idea of the $D S V$-specific hydA-gene relevance to $\mathrm{PD}$. KM, VH, TT, and PS designed the study. VH performed experiments and analyses under supervision of TT and PS. KM and VH wrote the first draft of the manuscript. TT and PS revised the manuscript, followed by the finalizing of the manuscript by all authors. PS acquired study funding. All authors contributed to the article and approved the submitted version.

\section{ACKNOWLEDGMENTS}

We thank Dr. David Fewer and Eric Schaedig for critically reading the manuscript and language corrections. We also thank Dr. Teppo Artturi Mattsson for statistical advice. The project was funded by the University of Helsinki.
Chapman, M. A. (2001). The Role of the Colonic Flora in Maintaining a Healthy Large Bowel Mucosa. Ann. R. Coll. Surg. Engl. 83 (2), 75-80.

Chen, S. G., Stribinskis, V., Rane, M. J., Demuth, D. R., Gozal, E., Roberts, A. M., et al. (2016). Exposure to the Functional Bacterial Amyloid Protein Curli Enhances Alpha-Synuclein Aggregation in Aged Fischer 344 Rats and Caenorhabditis Elegans. Sci. Rep. 6 (1), 34477. doi: 10.1038/srep34477

Chiang, H.-L., and Lin, C.-H. (2019). Altered Gut Microbiome and Intestinal Pathology in Parkinson's Disease. J. Mov. Disord. 12 (2), 67-83. doi: 10.14802/ jmd.18067

Chistyakova, N. I., Rusakov, V. S., Zavarzina, D. G., Slobodkin, A. I., and Gorohova, T. V. (2004). Mössbauer Study of Magnetite Formation by Ironand Sulfate-Reducing Bacteria. Hyperfine. Interact. 156 (1), 411-415. doi: 10.1023/B:HYPE.0000043261.17920.b9

Choi, J. G., Kim, N., Ju, I. G., Eo, H., Lim, S.-M., Jang, S.-E., et al. (2018). Oral Administration of Proteus Mirabilis Damages Dopaminergic Neurons and Motor Functions in Mice. Sci. Rep. 8 (1), 1275. doi: 10.1038/s41598-01819646-x

Derrien, M., Collado, M. C., Ben-Amor, K., Salminen, S., and de Vos, W. M. (2008). The Mucin Degrader Akkermansia Muciniphila is an Abundant Resident of the Human Intestinal Tract. Appl. Environ. Microbiol. 74 (5), 1646-1648. doi: 10.1128/AEM.01226-07

Earley, H., Lennon, G., Balfe, A., Kilcoyne, M., Clyne, M., Joshi, L., et al. (2015). A Preliminary Study Examining the Binding Capacity of Akkermansia Muciniphila and Desulfovibrio Spp., to Colonic Mucin in Health and Ulcerative Colitis. PLoS One 10 (10), e0135280. doi: 10.1371/journal.pone.0135280

Edwards, U., Rogall, T., Blöcker, H., Emde, M., and Böttger, E. C. (1989). Isolation and Direct Complete Nucleotide Determination of Entire Genes. Characterization of a Gene Coding for 16S Ribosomal RNA. Nucleic Acids Res. 17 (19), 7843-7853. doi: 10.1093/nar/17.19.7843

El-Agnaf, O. M., Salem, S. A., Paleologou, K. E., Curran, M. D., Gibson, M. J., Court, J. A., et al. (2006). Detection of Oligomeric Forms of Alpha-Synuclein Protein in Human Plasma as a Potential Biomarker for Parkinson's Disease. FASEB J. 20 (3), 419-425. doi: 10.1096/fj.03-1449com

Fite, A., Macfarlane, G. T., Cummings, J. H., Hopkins, M. J., Kong, S. C., Furrie, E., et al. (2004). Identification and Quantitation of Mucosal and Faecal Desulfovibrios Using Real Time Polymerase Chain Reaction. Gut 53 (4), 523. doi: 10.1136/gut.2003.031245 
Flannigan, K. L., Ferraz, J. G., Wang, R., and Wallace, J. L. (2013). Enhanced Synthesis and Diminished Degradation of Hydrogen Sulfide in Experimental Colitis: A Site-Specific, Pro-Resolution Mechanism. PLoS One 8 (8), e71962. doi: 10.1371/journal.pone.0071962

Forsyth, C. B., Shannon, K. M., Kordower, J. H., Voigt, R. M., Shaikh, M., Jaglin, J. A., et al. (2011). Increased Intestinal Permeability Correlates With Sigmoid Mucosa Alpha-Synuclein Staining and Endotoxin Exposure Markers in Early Parkinson's Disease. PLoS One 6 (12), e28032. doi: 10.1371/ journal.pone.0028032

Fröhlich, E., and Roblegg, E. (2012). Models for Oral Uptake of Nanoparticles in Consumer Products. Toxicology 291 (1-3), 10-17. doi: 10.1016/j.tox.2011.11.004

Fuke, N., Nagata, N., Suganuma, H., and Ota, T. (2019). Regulation of Gut Microbiota and Metabolic Endotoxemia With Dietary Factors. Nutrients 11 (10), 2277. doi: 10.3390/nu11102277

Gilder, S. A., Wack, M., Kaub, L., Roud, S. C., Petersen, N., Heinsen, H., et al. (2018). Distribution of Magnetic Remanence Carriers in the Human Brain. Sci. Rep. 8 (1), 11363. doi: 10.1038/s41598-018-29766-Z

Goldstein, E. J. C., Citron, D. M., Peraino, V. A., and Cross, S. A. (2003). Desulfovibrio Desulfuricans Bacteremia and Review of Human Desulfovibrio Infections. J. Clin. Microbiol. 41 (6), 2752-2754. doi: 10.1128/jcm.41.6.2752-2754.2003

Gorecki, A. M., Preskey, L., Bakeberg, M. C., Kenna, J. E., Gildenhuys, C., MacDougall, G., et al. (2019). Altered Gut Microbiome in Parkinson's Disease and the Influence of Lipopolysaccharide in a Human $\alpha$-Synuclein Over-Expressing Mouse Model. Front. Neurosci. 13, 839. doi: 10.3389/ fnins.2019.00839

Guo, Z., Li, C. S., Wang, C. M., Xie, Y. J., and Wang, A. L. (2015). CSE/H2S System Protects Mesenchymal Stem Cells From Hypoxia and Serum Deprivation -Induced Apoptosis Via Mitochondrial Injury, Endoplasmic Reticulum Stress and PI3K/Akt Activation Pathways. Mol. Med. Rep. 12 (2), 2128-2134. doi: 10.3892/mmr.2015.3651

Haikal, C., Chen, Q.-Q., and Li, J.-Y. (2019). Microbiome Changes: An Indicator of Parkinson's Disease? Transl. Neurodegener. 8 (1), 38. doi: 10.1186/s40035019-0175-7

Hälldin, J., and Land, T. (2008). Sulfide Increases Labile Iron Pool in RD4 Cells. Biometals 21 (2), 127-131. doi: 10.1007/s10534-007-9099-2

Haouzi, P., Sonobe, T., and Judenherc-Haouzi, A. (2020). Hydrogen Sulfide Intoxication Induced Brain Injury and Methylene Blue. Neurobiol. Dis. 133, 104474. doi: 10.1016/j.nbd.2019.05.013

Hertel, J., Harms, A. C., Heinken, A., Baldini, F., Thinnes, C. C., Glaab, E., et al. (2019). Integrated Analyses of Microbiome and Longitudinal Metabolome Data Reveal Microbial-Host Interactions on Sulfur Metabolism in Parkinson's Disease. Cell Rep. 29 (7), 1767-1777.e1768. doi: 10.1016/j.celrep.2019.10.035

Hoehn, M. M., and Yahr, M. D. (1967). Parkinsonism: Onset, Progression and Mortality. Neurology 17 (5), 427-442. doi: 10.1212/wnl.17.5.427

Holmqvist, S., Chutna, O., Bousset, L., Aldrin-Kirk, P., Li, W., Björklund, T., et al. (2014). Direct Evidence of Parkinson Pathology Spread From the Gastrointestinal Tract to the Brain in Rats. Acta Neuropathol. 128 (6), 805820. doi: 10.1007/s00401-014-1343-6

Houser, M. C., and Tansey, M. G. (2017). The Gut-Brain Axis: Is Intestinal Inflammation a Silent Driver of Parkinson's Disease Pathogenesis? NPJ Parkinsons. Dis. 3, 3. doi: 10.1038/s41531-016-0002-0

Hughes, A. J., Daniel, S. E., Kilford, L., and Lees, A. J. (1992). Accuracy of Clinical Diagnosis of Idiopathic Parkinson's Disease: A Clinico-Pathological Study of 100 Cases. J. Neurol. Neurosurg. Psychiatry 55 (3), 181-184. doi: 10.1136/ jnnp.55.3.181

Jalanka, J., Major, G., Murray, K., Singh, G., Nowak, A., Kurtz, C., et al. (2019). The Effect of Psyllium Husk on Intestinal Microbiota in Constipated Patients and Healthy Controls. Int. J. Mol. Sci. 20 (2):433. doi: 10.3390/ijms20020433

Joppe, K., Roser, A.-E., Maass, F., and Lingor, P. (2019). The Contribution of Iron to Protein Aggregation Disorders in the Central Nervous System. Front. Neurosci. 13, 15. doi: 10.3389/fnins.2019.00015

Joshi, N., Basak, S., Kundu, S., De, G., Mukhopadhyay, A., and Chattopadhyay, K. (2015). Attenuation of the Early Events of $\alpha$-Synuclein Aggregation: A Fluorescence Correlation Spectroscopy and Laser Scanning Microscopy Study in the Presence of Surface-Coated Fe3O4 Nanoparticles. Langmuir 31 (4), 1469-1478. doi: 10.1021/la503749e

Kang, X., Ploner, A., Ludvigsson, J. F., Williams, D. M., Larsson, H., Pedersen, N. L., et al. (2020). Clostridium Difficile Infection and Risk of Parkinson's Disease:
A Swedish Population-Based Cohort Study. Eur. J. Neurol. 27 (11), 2134-2141. doi: 10.1111/ene.14400

Kelly, L. P., Carvey, P. M., Keshavarzian, A., Shannon, K. M., Shaikh, M., Bakay, R. A., et al. (2014). Progression of Intestinal Permeability Changes and AlphaSynuclein Expression in a Mouse Model of Parkinson's Disease. Mov. Disord. 29 (8), 999-1009. doi: 10.1002/mds.25736

Konhauser, K. O. (1997). Bacterial Iron Biomineralisation in Nature. FEMS Microbiol. Rev. 20 (3-4), 315-326. doi: 10.1111/j.1574-6976.1997.tb00317.x

Kumar, A., Ganini, D., and Mason, R. P. (2016). Role of Cytochrome C in $\alpha$ Synuclein Radical Formation: Implications of $\alpha$-Synuclein in Neuronal Death in Maneb- and Paraquat-Induced Model of Parkinson's Disease. Mol. Neurodegener. 11 (1), 70. doi: 10.1186/s13024-016-0135-y

Lenders, J. J. M., Mirabello, G., and Sommerdijk, N. A. J. M. (2016). Bioinspired Magnetite Synthesis Via Solid Precursor Phases. Chem. Sci. 7 (9), 5624-5634. doi: 10.1039/C6SC00523C

Libiad, M., Yadav, P. K., Vitvitsky, V., Martinov, M., and Banerjee, R. (2014). Organization of the Human Mitochondrial Hydrogen Sulfide Oxidation Pathway. J. Biol. Chem. 289 (45), 30901-30910. doi: 10.1074/jbc.M114.602664

Li, X., Dong, C., Hoffmann, M., Garen, C. R., Cortez, L. M., Petersen, N. O., et al. (2019). Early Stages of Aggregation of Engineered $\alpha$-Synuclein Monomers and Oligomers in Solution. Sci. Rep. 9 (1), 1734. doi: 10.1038/s41598-018-37584-6

Lin, C.-H., Lin, J.-W., Liu, Y.-C., Chang, C.-H., and Wu, R.-M. (2014). Risk of Parkinson's Disease Following Severe Constipation: A Nationwide PopulationBased Cohort Study. Parkinsonism. Relat. Disord. 20, 1371-1375. doi: 10.1016/ j.parkreldis.2014.09.026

Lin, A., Zheng, W., He, Y., Tang, W., Wei, X., He, R., et al. (2018). Gut Microbiota in Patients With Parkinson's Disease in Southern China. Park. Relat. Disord. 53, 82-88. doi: 10.106/j.parkreldis.2018.05.007

Loubinoux, J., Bronowicki, J. P., Pereira, I. A., Mougenel, J. L., and Faou, A. E. (2002). Sulfate-Reducing Bacteria in Human Feces and Their Association With Inflammatory Bowel Diseases. FEMS Microbiol. Ecol. 40 (2), 107-112. doi: 10.1111/j.1574-6941.2002.tb00942.x

Lovley, D. R., Roden, E. E., Phillips, E. J. P., and Woodward, J. C. (1993). Enzymatic Iron and Uranium Reduction by Sulfate-Reducing Bacteria. Mar Geol. 113 (1), 41-53. doi: 10.1016/0025-3227(93)90148-O

Mappin-Kasirer, B., Pan, H., Lewington, S., Kizza, J., Gray, R., Clarke, R., et al. (2020). Tobacco Smoking and the Risk of Parkinson Disease. Neurology 94 (20), e2132. doi: 10.1212/WNL.0000000000009437

McGee, D. J., Lu, X. H., and Disbrow, E. A. (2018). Stomaching the Possibility of a Pathogenic Role for Helicobacter Pylori in Parkinson's Disease. J. Parkinsons. Dis. 8 (3), 367-374. doi: 10.3233/jpd-181327

Murros, K. E. (2020). Sulfate Reducing Gut Bacteria and Parkinson's Disease. Eur. J. Neurol. doi: 10.1111/ene.14626

Murros, K. E. (2021). Sulfate reducing gut bacteria and Parkinson's disease. Eur. J. Neurol. 28 (3), e21. doi: 10.1111/ene.14626

Murros, K., Wasiljeff, J., Macías-Sánchez, E., Faivre, D., Soinne, L., Valtonen, J., et al. (2019). Magnetic Nanoparticles in Human Cervical Skin. Front. Med. 6, 123. doi: $10.3389 /$ fmed.2019.00123

Nava, G. M., Carbonero, F., Croix, J. A., Greenberg, E., and Gaskins, H. R. (2012). Abundance and Diversity of Mucosa-Associated Hydrogenotrophic Microbes in the Healthy Human Colon. ISME. J. 6 (1), 57-70. doi: 10.1038/ismej.2011.90

Panthi, S., Manandhar, S., and Gautam, K. (2018). Hydrogen Sulfide, Nitric Oxide, and Neuro- Degenerative Disorders. Transl. Neurodegener. 7, 3. doi: 10.1186/ s40035-018-0108-x

Park, H. S., Lin, S., and Voordouw, G. (2008). Ferric Iron Reduction by Desulfovibrio Vulgaris Hildenborough Wild Type and Energy Metabolism Mutants. Antonie. Van. Leeuwenhoek. 93 (1-2), 79-85. doi: 10.1007/s10482-007-9181-3

Pereira, I. A., Ramos, A. R., Grein, F., Marques, M. C., da Silva, S. M., and Venceslau, S. S. (2011). A Comparative Genomic Analysis of Energy Metabolism in Sulfate Reducing Bacteria and Archaea. Front. Microbiol. 2:69. doi: $10.3389 /$ fmicb. 2011.00069

Picton, R., Eggo, M. C., Merrill, G. A., Langman, M. J. S., and Singh, S. (2002). Mucosal Protection Against Sulphide: Importance of the Enzyme Rhodanese. Gut 50 (2), 201-205. doi: 10.1136/gut.50.2.201

Ramasamy, S., Singh, S., Taniere, P., Langman, M. J., and Eggo, M. C. (2006). Sulfide-Detoxifying Enzymes in the Human Colon are Decreased in Cancer and Upregulated in Differentiation. Am. J. Physiol. Gastrointest. Liver. Physiol. 291 (2), G288-G296. doi: 10.1152/ajpgi.00324.2005 
Ruas-Madiedo, P., Gueimonde, M., Fernández-García, M., de los Reyes-Gavilán, C. G., and Margolles, A. (2008). Mucin Degradation by Bifidobacterium Strains Isolated From the Human Intestinal Microbiota. Appl. Environ. Microbiol. 74 (6), 1936-1940. doi: 10.1128/aem.02509-07

Rumbeiha, W., Whitley, E., Anantharam, P., Kim, D. S., and Kanthasamy, A. (2016). Acute Hydrogen Sulfide-Induced Neuropathology and Neurological Sequelae: Challenges for Translational Neuroprotective Research. Ann. N. Y. Acad. Sci. 1378 (1), 5-16. doi: 10.1111/nyas.13148

Scanlan, P. D., Shanahan, F., and Marchesi, J. R. (2009). Culture-Independent Analysis of Desulfovibrios in the Human Distal Colon of Healthy, Colorectal Cancer and Polypectomized Individuals. FEMS Microbiol. Ecol. 69 (2), 213221. doi: 10.1111/j.1574-6941.2009.00709.x

Scheperjans, F., Aho, V., Pereira, P. A. B., Koskinen, K., Paulin, L., Pekkonen, E., et al. (2015). Gut Microbiota are Related to Parkinson's Disease and Clinical Phenotype. Mov. Disord. 30, 350-358. doi: 10.1002/mds.26069

Shen, T., Yue, Y., He, T., Huang, C., Qu, B., Lv, E., et al. (2021). The Association Between the Gut Microbiota and Parkinson's Disease, a Meta-Analysis. Front. Aging Neurosci. 13, 636545. doi: 10.3389/fnagi.2021.636545

Singh, S. B., and Lin, H. C. (2015). Hydrogen Sulfide in Physiology and Diseases of the Digestive Tract. Microorganisms 3 (4), 866-889. doi: 10.3390/ microorganisms3040866

Stirpe, P., Hoffman, M., Badiali, D., and Colosimo, C. (2016). Constipation: An Emerging Risk Factor for Parkinson's Disease? Eur. J. Neurol. 0, 1-8. doi: 10.111/ene.13082

Sui, Y. T., Bullock, K. M., Erickson, M. A., Zhang, J., and Banks, W. A. (2014). Alpha Synuclein is Transported Into and Out of the Brain by the Blood-Brain Barrier. Peptides 62, 197-202. doi: 10.1016/j.peptides.2014.09.018

Swasthi, H. M., and Mukhopadhyay, S. (2017). Electrostatic Interaction Sequester the Curli Amyloid Fold on the Lipopolysaccharide Membrane Surface. J. Biol. Chem. 292, 19861-19872. doi: 10.1074/jbc.M117.815522
Tomasova, L., Dobrowolski, L., Jurkowska, H., Wróbel, M., Huc, T., Ondrias, K., et al. (2016). Intracolonic Hydrogen Sulfide Lowers Blood Pressure in Rats. Nitric. Oxide 60, 50-58. doi: 10.1016/j.niox.2016.09.007

Vandeputte, D., Kathagen, G., D’hoe, K., Vieira-Silva, S., Valles-Colomer, M., Sabino, J., et al. (2017). Quantitative Microbiome Profiling Links Gut Community Variation to Microbial Load. Nature 551 (7681), 507-511. doi: 10.1038/nature24460

Wallen, Z. D., Appah, M., Dean, M. N., Sesler, C. L., Factor, S. A., Molho, E., et al. (2020). Characterizing Dysbiosis of Gut Microbiome in PD: Evidence for Overabundance of Opportunistic Pathogens. NPJ Parkinsons. Dis. 6 (1), 11. doi: 10.1038/s41531-020-0112-6

Zabarovsky, E. R., and Winberg, G. (1990). High Efficiency Electroporation of Ligated DNA Into Bacteria. Nucleic Acids Res. 18 (19):5912. doi: 10.1093/nar/18.19.5912

Zhou, K. (2017). Strategies to Promote Abundance of Akkermansia Muciniphila, an Emerging Probiotics in the Gut, Evidence From Dietary Intervention Studies. J. Funct. Foods. 33, 194-201. doi: 10.1016/j.jff.2017.03.045

Zinkevich, V., and Beech, I. B. (2000). Screening of Sulfate-Reducing Bacteria in Colonoscopy Samples From Healthy and Colitic Human Gut Mucosa. FEMS Microbiol. Ecol. 34 (2), 147-155. doi: 10.1111/j.1574-6941.2000.tb00764.x

Conflict of Interest: The authors are inventors in a patent application submitted by Helsinki Innovation Services. This patent disclosure (Finnish patent application No. 20205685) is owned by the University of Helsinki.

Copyright (c) 2021 Murros, Huynh, Takala and Saris. This is an open-access article distributed under the terms of the Creative Commons Attribution License (CC BY). The use, distribution or reproduction in other forums is permitted, provided the original author(s) and the copyright owner(s) are credited and that the original publication in this journal is cited, in accordance with accepted academic practice. No use, distribution or reproduction is permitted which does not comply with these terms. 